\title{
Novel Classification Forms for Xenia
}

\author{
Qin Yang \\ College of Life and Health Science, Kaili University, Kaili, Guizhou 556000, \\ China
}

\section{Yan Fu \\ Qiandongnan Vocational and Technical College, Kaili, Guizhou 556000, China}

Yalan Liu, Tingting Zhang, Shu Peng, and Jie Deng
College of Life and Health Science, Kaili University, Kaili, Guizhou 556000,
China

Additional index words. Classification, combined xenia, double-fertilization xenia, metaxenia, non-double-fertilization xenia, photosynthetic capacity

\begin{abstract}
The xenia effect refers to the phenomenon whereby the pollen genotype directly affects seed and fruit development during the period from fertilization to seed germination, which leads to different characteristics in phenotypic traits. The xenia effect can create differences in the endosperm and embryo formed after double fertilization and can also alter various fruit parameters, such as the fruit-ripening period; the fruit shape, size, and color; the flavor quality, such as sugars and acids; as well as the nutrient quality, such as anthocyanins. The xenia effect manifests in various ways, playing an important role in increasing the yield of fruit trees, improving fruit appearance and internal quality, as well as in directional breeding. Compared with other pomology research areas, our understanding of the xenia effect is still in its infancy. Currently, xenia is classified into two types: xenia and metaxenia. In the former, the direct effects of the pollen genotype are exhibited in the syngamous parts of the ovules; that is, the embryo and endosperm only. In the latter, the effects of the pollen genotype are demonstrated in structures other than the embryo and endosperm; that is, in tissues derived wholly from the mother plant material, in seed parts such as the nucellus and testa, as well as in the carpels and accessory tissues. However, the current classification has various shortcomings. In the present study, we propose a novel classification based on whether the appearance of xenia results from the tissue formed by double fertilization. Three xenia types are proposed: double-fertilization xenia, non-double-fertilization xenia, and combined xenia. The new classification has great theoretical and practical significance for future studies on the xenia effect and its mechanisms and also provides a more effective, broader application of xenia in improving the yield and quality of fruit trees.
\end{abstract}

As early as 1868, Darwin devoted six pages to describe "the direct or immediate action of the male element on the mother form" in his book The Variation (Liu, 2008); a phenomenon that now we call xenia. Xenia refers to the direct effect of the pollen genotype on the development and characteristics of the seed and fruit in the period that spans fertilization to seed germination. During this period, xenia causes phenotypic variations in

\footnotetext{
Received for publication 18 Feb. 2020. Accepted for publication 20 Apr. 2020.

Published online 26 May 2020.

This work was supported by the Technology Cooperation Programme of the Guizhou Science and Technology Department of China (No. QIAN KE HE HL ZI [2016]7331) and the National Natural Science Foundation of China (No. 31860546).

We thank LetPub (www.letpub.com) for its linguistic assistance during the preparation of this manuscript.

Q.Y. is the corresponding author. E-mail: yangqin1028518@126.com.

This is an open access article distributed under the CC BY-NC-ND license (https://creativecommons. org/licenses/by-nc-nd/4.0/).
}

the seed and fruit that reflect the traits of the pollinizer parent; however, these traits are not inherited by the progeny. When the female and male reproductive cells combine, the pollen genotype can directly affect the maternal tissue outside the embryo and endosperm, such as the seedcoat and pericarp, and cause differences in the traits, color, and quality of the hybridized fruit and seed (Denney, 1992; Pozzi et al., 2019; Shi et al., 2008). Studies have shown that xenia is widely present in fruit trees. Not only does it affect the formation of the endosperm and embryo following double fertilization, but also causes differences in seed shape and size. It can also alter the fruit-ripening period (Mizrahi et al., 2004) (Fig. 1), fruit shape and size (Zhang et al., 2016b) (Fig. 2), color of the pericarp, fruit flavor, and the contents of certain substances (Kumar and Das, 1996; Zhou et al., 2011). Thus, studying the xenia effect has great significance in fruit production, of which fruit and seed are the main targets for harvest. It can also provide a theoretical reference for the pollination configuration of the cultivar, increased yield, improvements in internal and external fruit qualities, as well as in the genetics, physiology, and breeding science of fruit trees (Denney, 1992; Liu, 2008; Shi et al., 2008). Currently, many pomologists and horticulturists have realized the practical and theoretical importance of xenia; however, although the available studies have focused on the observation and classification of xenia, this classification is far from comprehensive.

As fruits and seeds are the targets of human consumption, the impact of xenia on phenotypic traits has been classified into two types: xenia and metaxenia (Denney, 1992; Liu, 2008; Shi et al., 2008). In xenia, the pollen genotype directly affects the seeds formed after fertilization in the female parent in the current year and causes differences in seed shape, size, and color. Metaxenia is the phenomenon whereby the pollen genotype directly affects the fruit shape, maturation period, size, color, flavor, and content of substances in the current year and results in variations in these traits (Denney, 1992; Shi et al., 2008; Zhou et al., 2011). In the late 19th century and early 20 th century, the definition of these two terminologies was one of the most discussed topics among scholars. In fact, the differentiation and definition of these two types of xenia, particularly relating to which kind of xenia the difference in the pericarp belongs to, still puzzles researchers today (Kahriman et al., 2017; Suaib and Suleman, 2018). Although xenia research in fruit trees has made great progress in recent years, we propose that the current classification of xenia and metaxenia is limited and hinders the progression of further xenia research. For example, the classification of xenia in Carya cathayensis Sarg., or Chinese hickory, is perplexing. Based on the currently accepted definitions of xenia, the xenia in $C$. cathayensis should be classified as xenia because the pollen genotype directly affects the seeds formed after fertilization in the female parent in the current year and causes differences in seed quality, oil content, and crude protein content (Wang et al., 2010). However, recent research has demonstrated that enhancing the photosynthetic capacity of the exocarp is the primary contributor to the differences in fruit enlargement in apomixis (Huang et al., 2019). It thus seems more reasonable to classify this as metaxenia based on the fundamental cause of the differences in the fruit.

In pomegranate, the pollen genotype not only significantly affects the fruit shape, length and diameter, fruit color, and fruit peel thickness, but also alters the seed weight, length and diameter, hardness, and toughness (Gharaghani et al., 2017), and thus cannot be classified into either type of xenia. These examples demonstrate that the current classification of xenia and metaxenia cannot reflect whether the tissue formed by xenia obtained paternal information through double fertilization. It also does not indicate the fundamental cause of the xenia. Thus, to facilitate the development of xenia research, it is necessary that the physiological processes of the formation of the organs and 
tissues that exhibit xenia are explored, focusing on whether the appearance of xenia resulted from tissue formed by double fertilization. Based on this, the present study offers a revised classification of xenia as three types: double-fertilization xenia, nondouble-fertilization xenia, and combined xenia. This novel xenia classification could offer great theoretical and practical significance in future research on xenia and its mechanisms, as well as a more effective, broader utilization of xenia to increase the yield and quality of fruit trees.

\section{Double-Fertilization Xenia}

Double-fertilization xenia refers to the phenomenon whereby the pollen genotype transfers information from the male parent via the double-fertilized tissue (embryo or endosperm) in the period from fertilization to seed germination, causing differences in the embryo, endosperm, and seedcoat, as well as in the fruit-ripening period, fruit shape, size, pericarp color, fruit flavor, and nutrient content. As Table 1 shows, double-fertilization xenia has been reported many times in Chi-

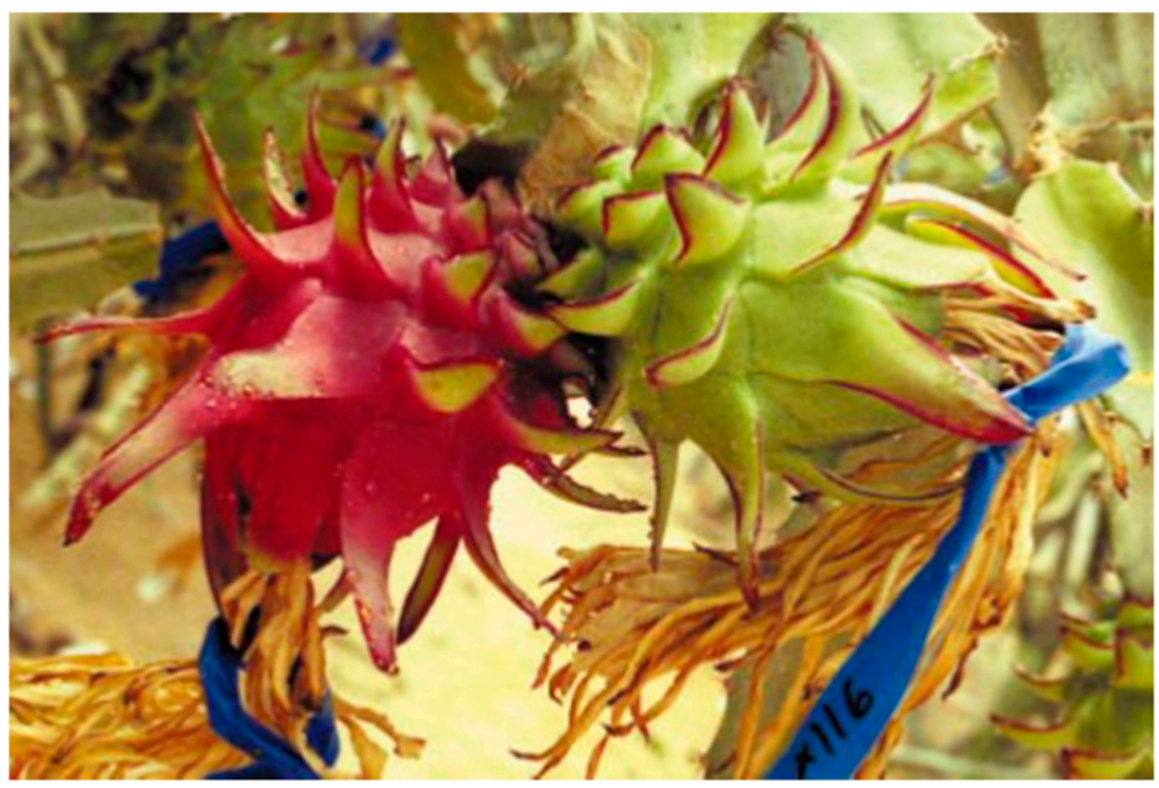

Fig. 1. A branch of Hylocereus polyrhizus bearing two fruits at different stages of ripening (Mizrahi et al., 2004). The red, ripe fruit originated from pollination with the pollen of Hylocereus undatus clones, whereas the green, unripe fruit resulted from pollination with Selenicereus grandiflorus pollen. This photograph was taken $34 \mathrm{~d}$ after pollination. nese chestnut (Castanea mollissima Blume), the seeds of which are mainly used for human consumption (Wang and Peng, 2015). The pollen genotype was found to affect the gene expression level of pyruvate phosphate dikinase in the leaves of $C$. mollissima and enhance its photosynthetic rate (Liang et al., 2016b), thereby causing a xenia effect in fruit size (Chen and Shi, 2009; Liang et al., 2016a; Lu et al., 2004), fruit shape, and single-fruit weight (Yang et al., 2018), and quantitative traits such as the content of starch and soluble sugar (Wang and Peng, 2015; Zhang et al., 2016a), fats, proteins, amylose, and vitamin $C$ (Wang and Peng, 2015; Zhang et al., 2016b). In peony, cross-pollination increased the number of seeds per fruit, seed volume, and seed and kernel weight (Xie et al., 2017) and upregulated the expression of 10 genes related to fatty acid and triglyceride biosynthesis during seed development (Xie et al., 2019), leading to an increased content of three unsaturated fatty acids: oleic acid, linoleic acid, and $\alpha$-linolenic acid (Xie et al., 2017).

When common corn is pollinated with high-oil corn, the development and growth of the embryo in the corn is promoted, and the weight of the embryo is significantly increased (Dong, 2007). In addition, when inducer lines with anthocyanin markers, such as R1-Navajo, which in combination with other dominant genes in the anthocyanin synthesis pathway causes deep pigmentation of the endosperm tissue in the crown region of the kernel and purple pigmentation in the embryo tissue, are crossed (as the male parent) with the source germplasm (as the female parent) lacking anthocyanin color markers, all the resulting hybrid kernels are expected to express the Navajo phenotype in the endosperm and embryo (Prasanna et al., 2012) (Fig. 3). Furthermore, the content of

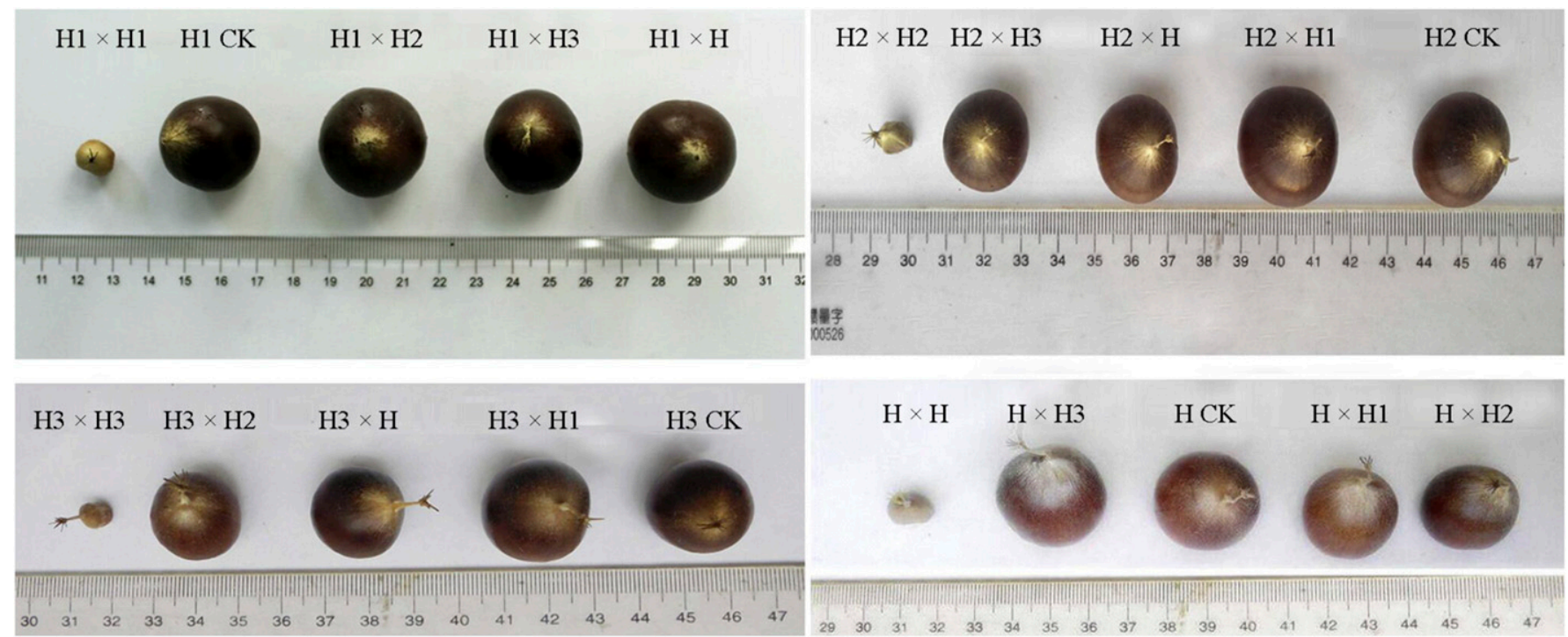

Fig. 2. Comparisons of the fruit sizes and colors for different pollination combinations (Zhang et al., 2016b). $\mathrm{H} 1=\mathrm{Huali} 1 ; \mathrm{H} 2=\mathrm{Huali} 2 ; \mathrm{H} 3=\mathrm{Huali} 3$; $\mathrm{H}=$ Huangzhen; $\mathrm{CK}=$ natural pollination. Huali 1 and Huali 2 pollinated by Huangzhen resulted in lighter-skinned fruits compared with the fruits resulting from natural pollination for these two varieties, whereas Huangzhen pollinated by Huali 2 and Huali 3 resulted in a darker-skinned fruit. These results were consistent with the color of the pollen donors. In contrast, Huali 3 pollinated by Huali 2 resulted in a lighter-skinned fruit than the skin color of the pollen donor. 
Table 1. Phenotypic characteristics of double-fertilization xenia in some plants.

\begin{tabular}{|c|c|c|c|}
\hline No. & Species & Phenotypic characteristics of xenia & Reference \\
\hline 1 & $\begin{array}{l}\text { Chestnut (Castanea } \\
\text { mollissima BL.) }\end{array}$ & Soluble sugar content, starch content & Wang and Peng (2015) \\
\hline 2 & Chestnut (C. mollissima BL.) & Fruit size, starch content, pyruvate phosphate dikinase, photosynthesis & Liang et al. (2016b) \\
\hline 3 & Chestnut (C. mollissima BL.) & Fruit size & Chen and Shi (2009) \\
\hline 4 & Chestnut (C. mollissima BL.) & Fruit size, number of nuts in cupula & Liang et al. (2016a) \\
\hline 5 & Chestnut (C. mollissima BL.) & Fruit shape, single-fruit weight & Yang et al. (2018) \\
\hline 6 & Chestnut (C. mollissima BL.) & Fruit size, average weight of nut & Lu et al. (2004) \\
\hline 7 & $\begin{array}{l}\text { Henry chestnut (Castanea } \\
\text { henryi } \mathrm{RW} .)\end{array}$ & Soluble sugars, fats, proteins, amylose, vitamin C & Zhang et al. (2016a) \\
\hline 8 & Henry chestnut ( $C$. henryi RW.) & Soluble sugars content, fats, proteins, amylose, vitamin C & Zhang et al. (2016b) \\
\hline 9 & $\begin{array}{l}\text { Tree peony (Paeonia } \\
\text { section Moutan DC.) }\end{array}$ & $\begin{array}{l}\text { Number of seeds per fruit, seed volume, seed and kernel weights, } \\
\text { linoleic acid concentration, oleic acid concentration, } \\
\text { oil extraction ratio, fatty acid composition }\end{array}$ & Xie et al. (2017) \\
\hline 10 & $\begin{array}{l}\text { Tree peony (Paeonia } \\
\text { section Moutan DC.) }\end{array}$ & Fatty acid and triacylglycerol biosynthetic pathway genes & Xie et al. (2019) \\
\hline 11 & Maize (Zea mays L.) & Embryo development and growth, embryo weight & Dong (2007) \\
\hline 12 & Maize (Z. mays L.) & Total unsaturated fatty acids & Chen and Dong (2017) \\
\hline 13 & Maize (Z. mays L.) & Color of endosperm and embryo & Prasanna et al. (2012) \\
\hline 14 & $\begin{array}{l}\text { Almonds (Amygdalus } \\
\text { communis L.) }\end{array}$ & Amygdalin content & Sánchez-Pérez et al. (2012) \\
\hline 15 & Almonds (A. communis L.) & Fatty acid composition & Alizadeh-Salte et al. (2018) \\
\hline 16 & Almonds (A. communis L.) & $\begin{array}{l}\text { Oleic acid, fatty acid composition, tocopherol concentrations, } \\
\text { linoleic acid ratio }\end{array}$ & Kodad et al. (2009) \\
\hline 17 & Clementine (Citrus) & Fruit yield, fresh weight, number of seeds per fruit & Papadakis et al. (2009) \\
\hline 18 & Mandarins (Citrus) & $\begin{array}{l}\text { Single-fruit weight, soluble solids and total acid content, } \\
\text { number of seeds per fruit }\end{array}$ & Yildiz and Kaplankıran (2017) \\
\hline 19 & Ponkan (Citrus) & $\begin{array}{l}\text { Total soluble solids, total sugars, polyphenolic and antioxidant capacities, } \\
\text { titratable acidity, carotenoid content, total polyphenolic content, } \\
\text { free radical-scavenging }\end{array}$ & Wang et al. (2018) \\
\hline 20 & Pummelo (Citrus) & $\begin{array}{l}\text { Contents of indole-3-acetic acid (IAA), gibberellic acid (GA) })_{1+3} \text {, } \\
\text { and cytokinins (CTKs) }\end{array}$ & Nie and Liu (2002) \\
\hline 21 & Pummelo (Citrus) & $\begin{array}{l}\text { Cis- and trans-linalool oxides contents, cytochrome P450 78A7 gene, } \\
\text { fruit aroma quality, linalool oxide synthase gene }\end{array}$ & Zhang et al. (2019a) \\
\hline
\end{tabular}

oleic acid in the kernels increased significantly, while the content of stearic acid, linoleic acid, and linolenic acid decreased. At maturity, the kernels from the hybridized generation contained higher amounts of total unsaturated fatty acids than the kernels from the selfed common corn (Chen and Dong, 2017).

In Citrus, cross-pollination increased the number of seeds per fruit (Papadakis et al., 2009; Yildiz and Kaplankıran, 2017) and the contents of indole-3-acetic acid (IAA), gibberellic acid $(\mathrm{GA})_{1+3}$, and cytokinins (CTKs) (Nie and Liu, 2002), thereby causing a xenia effect in quantitative traits such as the content of soluble solids, total acid, total sugars, titratable acidity, antioxidants, carotenoids, and total polyphenolics (Wang et al., 2018; Yildiz and Kaplankıran, 2017). Furthermore, cross-pollination upregulated the expression of the cytochrome P450 78A7 gene and linalool oxide synthase gene, which are associated with fruit aroma quality, leading to increased contents of cisand trans-linalool oxides (Zhang et al., 2019a). In addition, the pollen genotype in almond could regulate the amount of amygdalin transported from the embryo to the seedcoat, thereby affecting the taste (Sánchez-Pérez et al., 2012). It could also control the amount of unsaturated fatty acids, including oleic acid and linoleic acid (Alizadeh-Salte et al., 2018) and tocopherol concentrations (Kodad et al., 2009) in the almond kernels.

\section{Non-Double-Fertilization Xenia}

Non-double-fertilization xenia refers to the phenomenon whereby the pollen genotype transfers information from the male parent through non-double, or single, fertilization pathways during the period from fertilization to seed germination, which then causes differences in the embryo, endosperm, and seedcoat, as well as fruit-ripening period, fruit shape, size, pericarp color, flavor, and nutrient content. As indicated in Table 2, the pollen genotype in red bayberry could regulate the activity of sucrose phosphate synthase and sucrose synthase, significantly affecting the fruit color, quality, size, hardness, content of soluble solids, total sugars, vitamin $\mathrm{C}$, and titratable acids (Qi et al., 2017). When $C$. cathayensis was pollinated with the pollen from Carya illinoinensis (Wangenh.) K. Koch, or pecan nut, the pericarp of C. cathayensis became green (Fig. 4), and the genes related to photosynthetic pathways, including chlorophyll synthesis, light harvest, and carbon fixation, were upregulated (Huang et al., 2019; Xu et al., 2017). The exocarp of the fruit exhibited an enhanced photosynthetic rate, resulting in increased fruit biomass, fruit length, fruit diameter, shell thickness, shell weight, nut weight, and dry weight (Wang et al., 2010; $\mathrm{Xu}$ et al., 2017).

In kiwifruit, cross-pollination caused a xenia effect in fruit mass, fruit shape, transverse diameter, longitudinal diameter, and flesh firmness (Qi et al., 2007), and increased the contents of quantitative traits, including soluble solids, total sugar, total acid, titratable acid, vitamin $\mathrm{C}$, total polyphenols, total flavonoids, chlorophyll, and carotenoids (Seyrek et al., 2017; Xiao et al., 2013). In apple, cross-pollination caused a xenia effect in the fruit stalk, fruit lenticel, flesh cell interspace, flesh cell size (Li et al., 2016), fruit longitudinal diameter, fruit transverse diameter, fruit shape index (Yu et al., 2017), and single-fruit weight (Zhang et al., 2019b), and increased quantitative traits such as fruit hardness and the content of anthocyanins, soluble sugar, soluble solids, acidity, vitamin $\mathrm{C}$, total phenolics, total flavonoids, volatiles, and other characteristic compounds (Wang et al., 2016; Yu et al., 2017; Zhang et al., 2018, 2019b).

In addition, the pollen genotype in pear results in a xenia effect in external appearance, such as fruit size, fruit shape index, and lenticels on fruit skins (Lee et al., 2017; Stern et al., 2018), as well as in quantitative traits such as single-fruit weight, fruit firmness, soluble solid content, titratable acidity, vitamin C (Liu et al., 2016; Mansur et al., 2019; Sha et al., 2006), sugar, amino acids, fatty acid content, lignin synthesis, and stone cells (Li et al., 2018). In blueberry, crosspollination causes a xenia effect in fruitripening time, fruit size, and single-fruit weight (Ehlenfeldt and Kramer, 2012; Miller et al., 2011; Taber and Olmstead, 2016), resulting in a xenia effect in the external 


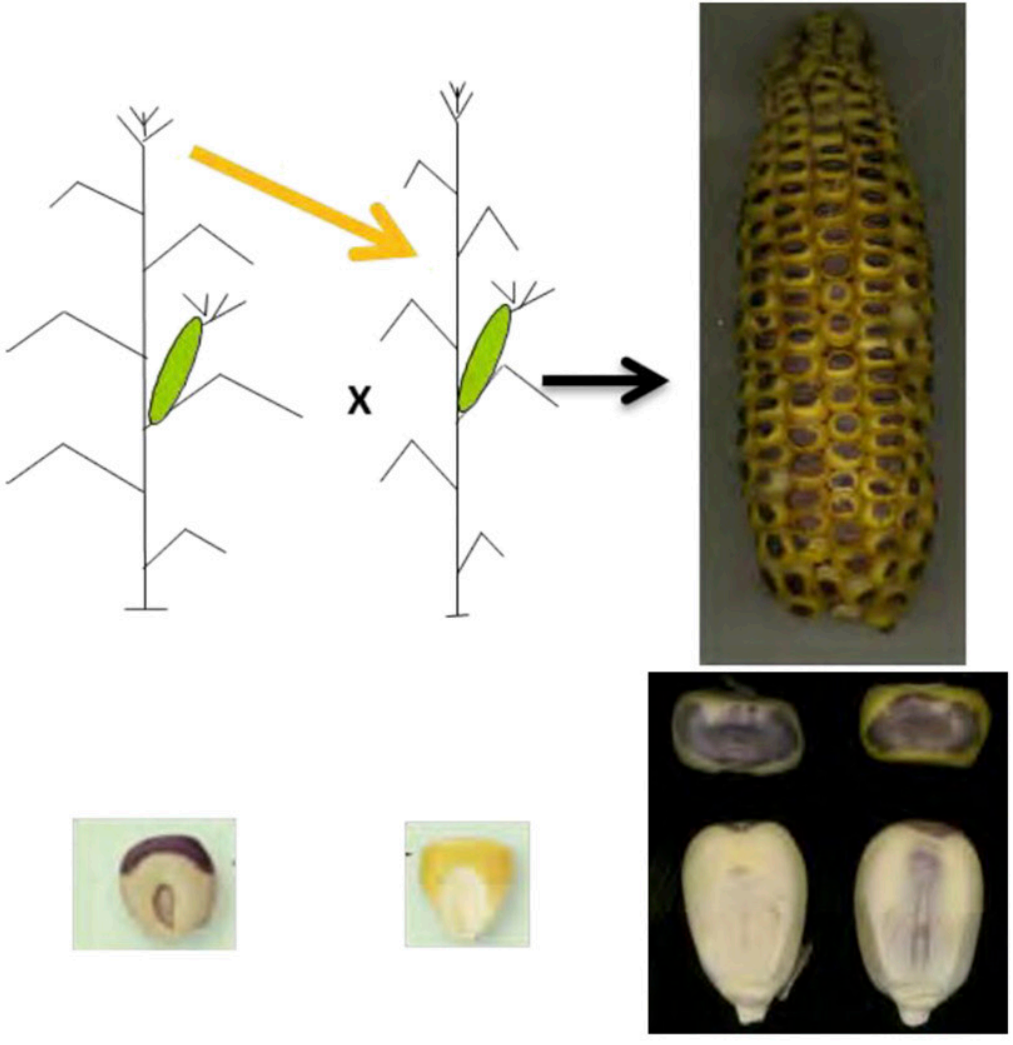

Male

Female

Hybrid

On the scutellum (embryo) expression

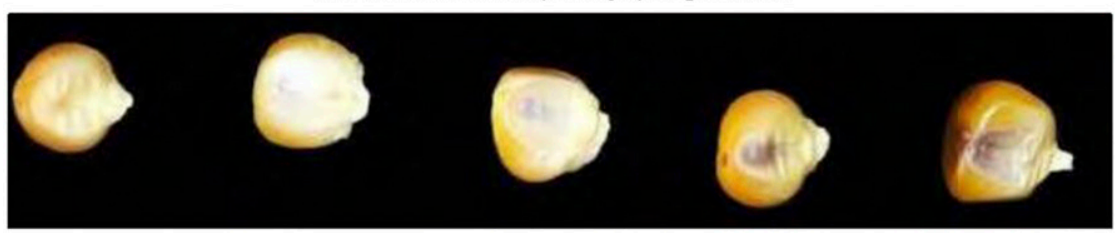

On the endosperm expression

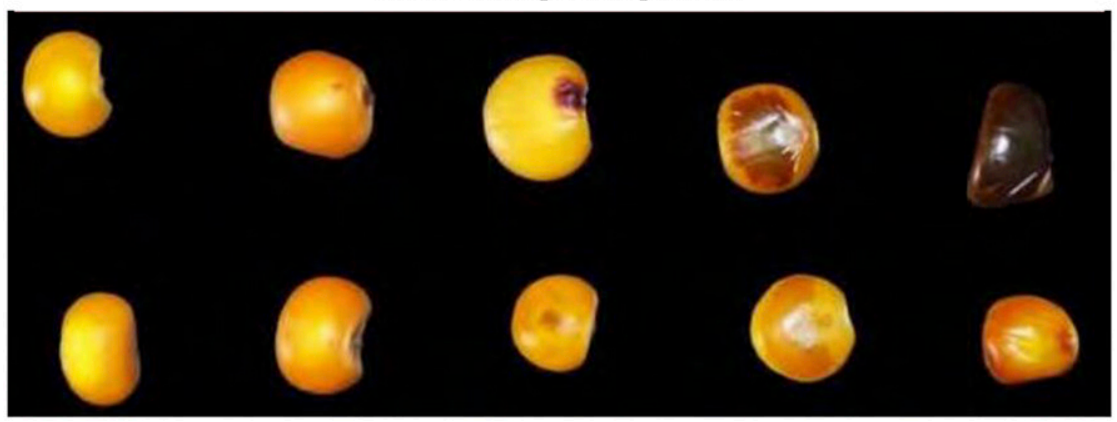

Fig. 3. As reported by Prasanna et al. (2012), when inducer lines with anthocyanin markers, such as R1Navajo, which in combination with other dominant genes in the anthocyanin synthesis pathway causes deep pigmentation of the endosperm tissue in the crown region of the kernel and purple pigmentation in the embryo tissue, are crossed (as the male parent) with the source germplasm (as the female parent) lacking the anthocyanin color markers, all the resulting hybrid kernels are expected to express the Navajo phenotype in the endosperm and in the embryo.

appearance, such as in the pedicel and sepal, as well as fruit depression, altered fruit shape, and fruit stem separation. This xenia also has an impact on the nutritional quality, such as

the soluble solid content, anthocyanin content, and total acid content (Yang et al., 2015; Yang et al., 2017). Cross-pollination causes a xenia effect in single-fruit weight as well as in the contents of soluble solids, titratable acid, total sugar, and vitamin $\mathrm{C}$ in plum (Zhang et al., 2017); in fruit size, soluble solid content, and firmness in peach (Shen et al., 2011); and in fruit size, single-fruit weight, and polysaccharide content in wolfberry (He et al., 2013).

\section{Combined Xenia}

Combined xenia refers to the phenomenon whereby the pollen genotype transfers information from the male parent via the double-fertilized tissue (embryo or endosperm) and non-double-fertilized tissue during the period from fertilization to seed germination, causing differences in the embryo, endosperm, seedcoat, fruit maturation period, fruit shape, size, pericarp color, fruit flavor, and nutrient content. As indicated in Table 3, the pollen genotype in tomato not only influences the pilose on the tomato fruit, but also affects the seed size (Piotto et al., 2013) (Fig. 5). In macadamia, the pollen genotype significantly influences the timing of embryo and endosperm development, kernel mass, timing of the hardening of the husk, shell mass, pericarp mass (Herbert et al., 2019a, 2019b), nut setting, nut apical papilla size, stalk length and thickness, nut transverse diameter, nut shape index, kernel rate, amino acid composition, aspartic acid content, oleic acid content, linoleic acid content, and total sugar content (He et al., 2016).

The pollen genotype not only significantly affects the fruit shape and length, single-fruit weight and diameter, fruit peel color (Fig. 6), fruit peel thickness, soluble solid contents, and lignin contents of pomegranate, but also significantly affects the aril color (Fig. 6), seed weight, seed length and diameter, seed hardness, seed toughness, and 1000-seed weight (Gharaghani et al., 2017; Xue et al., 2016). Similar results have also been reported in grape, namely that the pollen genotype directly affects the berries and seeds formed after fertilization in the female parent in the current year and causes differences in berry set, berry weight, berry length and width, as well as the number of seeds per berry, viable seed rate, seed size, 100 -seed weight, and seed width, height, and thickness (Sabir, 2011, 2015). In litchi, crosspollination causes a xenia effect in fruit size, fruit shape index, fruit weight, flesh recovery, skin thickness, total soluble solid contents, total sugars, vitamin $\mathrm{C}$, total acid, the sugaracid ratio, flesh texture and flavor, fruit cracking incidence, maturation date, and seed traits (Liu et al., 2011), as well as the contents of anthocyanins and chlorophyll in the peel (Qiu et al., 2006).

\section{Discussion}

The effect of xenia is of great agronomic importance for the production of fruits and seeds, having applications in plant breeding and in increasing grain yield or the size and quality of fruit (Pozzi et al., 2019). Although the practical importance of xenia has been 
Table 2. Phenotypic characteristics of the non-double-fertilization xenia in some plants.

\begin{tabular}{|c|c|c|c|}
\hline No. & Species & Phenotypic characteristics of xenia & Reference \\
\hline 1 & Red bayberry (Myrica rubra) & Soluble solids, total soluble sugars, titratable acids & Qi et al. (2017) \\
\hline 2 & Hickory (Carya cathayensis) & Chlorophyll synthesis, light capture, and carbon assimilation & Huang et al. (2019) \\
\hline 3 & Hickory (C. cathayensis) & Fruit size, exocarp color, photosynthetic rate & Xu et al. (2017) \\
\hline 4 & Hickory (C. cathayensis) & $\begin{array}{l}\text { Exocarp color, fruit shape, single-fruit weight, fruit length, } \\
\text { fruit diameter, fruit shape index, shell thickness, }\end{array}$ & Wang et al. (2010) \\
\hline
\end{tabular}

$5 \quad$ Kiwifruit (Actinidia chinensis Planch) shell weight, and nut weight

$6 \quad$ Kiwifruit (A. chinensis Planch)

Fruit mass, soluble solids content, transverse diameter, longitudinal diameter, fruit shape index, flesh firmness, fruit shape

Qi et al. (2007)

Fruit shape, single-fruit weight, soluble solids content, total sugar content, Xiao et al. (2013) total acid content, vitamin $\mathrm{C}$ content

$7 \quad$ Kiwifruit (Actinidia eriantha Vines)

Dry matter, total sugar, titratable acid, vitamin C, total polyphenol, total flavonoid, chlorophyll and carotenoid contents

Fruit stalk, fruit lenticel, flesh cell interspace, flesh cell size

Single-fruit weight, fruit shape index, hardness, anthocyanin, soluble sugar content, soluble solids

$8 \quad$ Apple (Malus domestica L.)

$9 \quad$ Apple (M. domestica L.)

10 Apple (M. domestica L.)

11 Xinjiang wild apple (Malus sieversii L.)

12 Apple (M. domestica L.)

Volatile and characteristic compounds

Fruit longitudinal diameter, fruit transverse diameter, shape index, acidity, soluble solid content, fruit stalk length

Single-fruit weight, fruit firmness, vitamin C content, sugar-acid ratio, total phenolics and total flavonoids, valuable phenolic compounds

Fruit setting, fruit weight, soluble solids content, titratable acidity

Jingbaili pear (Pyus ussuriensis)

14 Dangshan Su pear (Pyrus bretschneideri)

15 Korla Fragrant pear (Pyrus)

16 Qing Xiang pear (Pyrus)

17 'Niitaka' pears (Pyrus pyrifolia Nakai)

18 European pears (Pyrus communis)

19 Blueberry (Vaccinium spp.)

20 Blueberry (Vaccinium spp.)

21 Blueberry (Vaccinium spp.)

22 Blueberry (Vaccinium spp.)

23 Blueberry (Vaccinium spp.)

Sugar, amino acid, and fatty acid content, lignin synthesis, stone cell

Single-fruit weight, fruit firmness, fruit shape index, sugar-acid ratio, content of soluble solids and vitamin C

Single-fruit weight, hardness, soluble solids content, soluble sugar content, vitamin $\mathrm{C}$ content

Fruit size, external appearance, fruit shape index, lenticels on fruit skins Fruit size

Single-fruit weight, fruit size

Fruit size, fruit-ripening time

Single-fruit weight, fruit size, fruit-ripening time

Single-fruit weight, soluble solid content

Single-fruit weight, longitudinal diameter, fruit diameter, fruit shape index, fruit depression, pedicel, sepal, fruit shape and fruit stem separation, soluble solid content, anthocyanins content, total acid content

24 European plum (Prunus domestica L.) Single-fruit weight, soluble solids contents, titratable acids contents, total sugar content, vitamin $\mathrm{C}$ content

Fruit size, soluble solid content and firmness

Seyrek et al. (2017)

Li et al. (2016)

Zhang et al. (2018)

Wang et al. (2016)

Yu et al. (2017)

Zhang et al. (2019a)

Sha et al. (2006)

Li et al. (2018)

Mansur et al. (2019)

Liu et al. (2016)

Lee et al. (2017)

Stern et al. (2018)

Miller et al. (2011)

Ehlenfeldt and Kramer (2012)

Taber and Olmstead (2016)

Yang et al. (2015)

Yang et al. (2017)

Zhang et al. (2017)

Shen et al. (2011)

Fruit size, single-fruit weight, polysaccharide content

He et al. (2013)

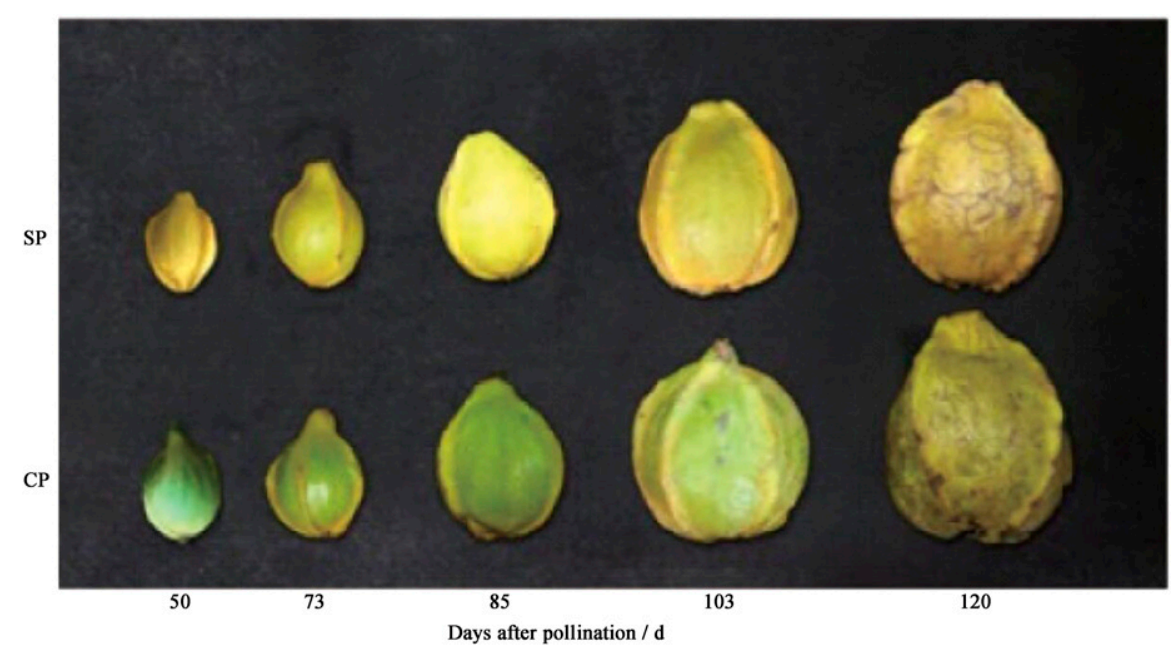

Fig. 4. Xu et al. (2017) reported on the changes in the shape of hickory fruits pollinated with two different pollens following pollination. The hickory fruits cross-pollinated (CP) by pecan pollen were significant larger and greener than those self-pollinated (SP) by hickory pollen.

realized by many agronomists and horticulturists, its mechanism remains poorly understood, and there has been very little focus on the physiological and molecular mechanisms

of xenia (Liu, 2008). In previous studies on xenia, researchers initially primarily focused on the xenia phenomenon of the edible portion of the fruit. For instance, in C. mollissima
(Wang and Peng, 2015) and C. cathayensis (Wang et al., 2010), studies were mainly concerned with the seed portion and were less concerned with the fruit portion. In contrast, in pear (Stern et al., 2018) and apple (Wang et al., 2017), studies were mainly concerned with the fruit portion rather than the seed portion. Thus, the classification of xenia into two types, namely xenia and metaxenia (Denney, 1992; Liu, 2008; Shi et al., 2008), was based only on the xenia exhibited in the edible portion. However, this classification is highly limited, as studies focused on the xenia of the edible seed part neglected the xenia of the fruit part, and vice versa. This led us to speculate that there was no xenia in the fruits of $C$. cathayensis and that the formation of xenia in C. cathayensis was due to differences in the seed following double fertilization. In addition, recent research suggests that enhanced photosynthesis in C. cathayensis plays an important role in the xenia of the pollen (Huang et al., 2019).

The xenia in Citrus, including clementine, mandarins, ponkan, and pummelo, could be classified as metaxenia according to the edible portion. However, previous studies have shown that cross-pollination increases the number of seeds per fruit in Citrus (Papadakis 
Table 3. Phenotypic characteristics of the combined xenia in some plants.

\begin{tabular}{|c|c|c|c|}
\hline No. & Species & Phenotypic characteristics of xenia & Reference \\
\hline 1 & Tomato (Solanum lycopersicum) & Fruit size, pilosity, seed weight & Piotto et al. (2013) \\
\hline 2 & $\begin{array}{l}\text { Macadamia (Macadamia ternifolia } \\
\text { F. Muell.) }\end{array}$ & Nut and kernel size, kernel mass, kernel recovery & Herbert et al. (2019a) \\
\hline 3 & Macadamia (M. ternifolia F. Muell.) & Nut mass, kernel mass, and kernel recovery & Herbert et al. (2019b) \\
\hline 4 & Macadamia (M. ternifolia F. Muell.) & $\begin{array}{l}\text { Nut setting, nut apical papilla size, stalk length and thickness, } \\
\text { nut transverse diameter, nut shape index, kernel rate, amino acid composition, } \\
\text { aspartic acid content, oleic acid content, linoleic acid content and total sugar content }\end{array}$ & He et al. (2016) \\
\hline 5 & Pomegranate (Punica granatum L.) & $\begin{array}{l}\text { Fruit shape, length, diameter, color, fruit peel thickness. Seed weight, } \\
\text { length, diameter, hardness, toughness }\end{array}$ & Gharaghani et al. (2017) \\
\hline 6 & Pomegranate $(P$. granatum L.) & $\begin{array}{l}\text { Fruit shape index, single-fruit weight, soluble solids contents, } \\
\text { lignin contents, number of seeds, edible rate. Aril juice yield, } \\
\text { seed hardness, } 1000 \text {-seed weight. }\end{array}$ & Xue et al. (2016) \\
\hline 7 & Grape 'Narince' (Vitis vinifera L.) & Berry set, berry and seed sizes, seed number per berry, percentage of viable seeds & Sabir (2015) \\
\hline 8 & Grape 'Italia' (V. vinifera L.) & $\begin{array}{l}\text { Berry setting, seed number per berry, viable seed rate, seed sizes, } 100 \text {-seed weight, } \\
\text { seed width, height, and thickness }\end{array}$ & Sabir (2011) \\
\hline 9 & $\begin{array}{l}\text { Litchi 'Dongliu No. 1' } \\
\text { (Litchi chinensis Sonn.) }\end{array}$ & $\begin{array}{l}\text { Fruit size, fruit shape index, flesh recovery, skin thickness, soluble solids contents, } \\
\text { total sugars, vitamin } \mathrm{C} \text { and total acid, sugar-acid ratio, flesh texture and flavor, } \\
\text { fruit cracking incidence, maturation date, seed traits }\end{array}$ & Liu et al. (2011) \\
\hline 10 & Litchi 'Guiwei' (L. chinensis Sonn.) & $\begin{array}{l}\text { Fruit longitudinal diameter, fruit shape index, fruit weight, flesh recover rate, } \\
\text { total soluble solids, contents of sugars, acid and vitamin } \mathrm{C} \text { in juice, } \\
\text { contents of anthocyanins and chlorophyll in peel }\end{array}$ & Qiu et al. (2006) \\
\hline
\end{tabular}
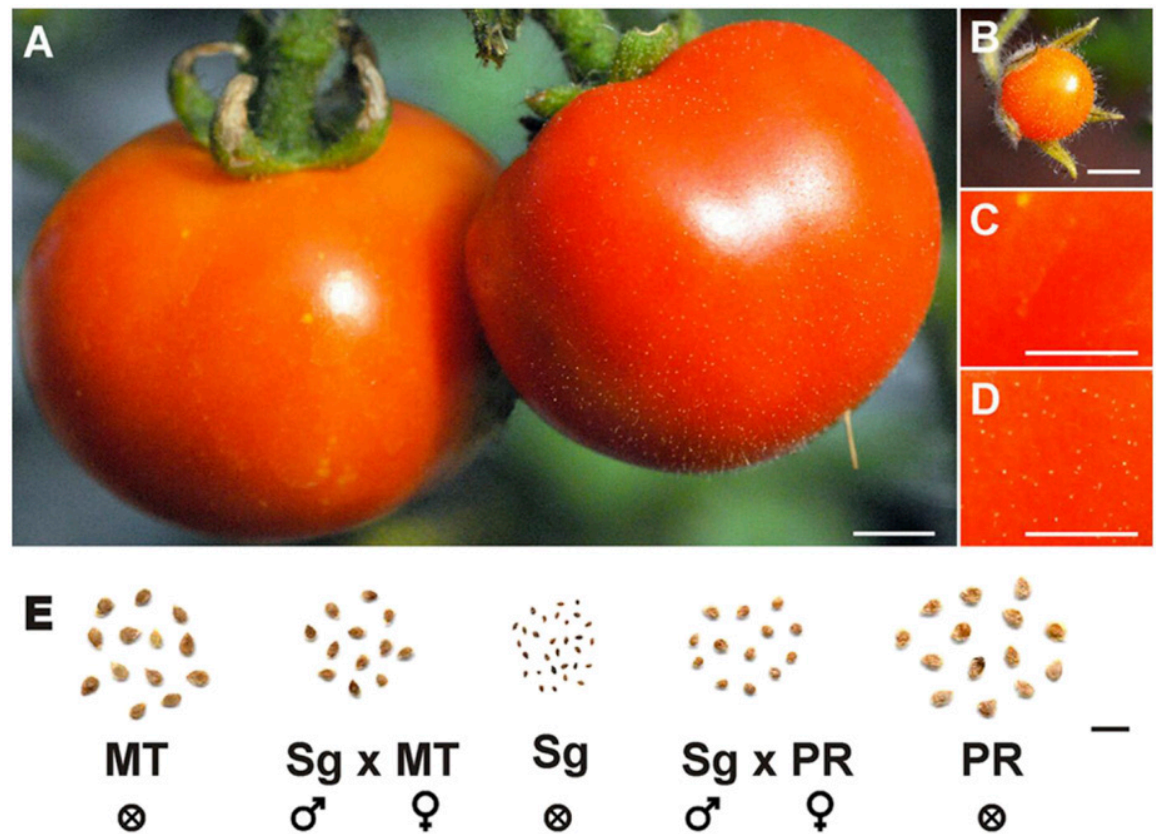

$\otimes$

Fig. 5. Piotto et al. (2013) reported the effect of Solanum galapagense $(\mathrm{Sg})$ pollen on the trichome density of cultivar Micro-Tom (MT) and on the seed weight of both cultivar MT and cultivar Pusa Ruby (PR) (A) Increase in trichome number in the fruits of cultivar MT pollinated by S. galapagense (left) compared with fruits from the same plant obtained by selfing (right); (B) fruit of $S$. galapagense showing a high trichome density; (C) epidermis of the selfed MT fruit showing low trichome density; (D) epidermis of the MT fruit after pollination by $S$. galapagense; (E) reduction in the seed size of cultivar MT and cultivar PR following pollination by $S$. galapagense $(\mathrm{Sg} \times \mathrm{MT}$ and $\mathrm{Sg} \times \mathrm{PR})$. MT, $\mathrm{Sg}$, and PR are selfed seeds. Bar $=5 \mathrm{~mm}$.

et al., 2009; Yildiz and Kaplankıran, 2017) as well as the contents of IAA, $\mathrm{GA}_{1+3}$, and CTKs (Nie and Liu, 2002), thereby causing a xenia effect in nutrient quality traits (Wang et al., 2018; Yildiz and Kaplankıran, 2017). These results suggested that the xenia was due to the differences in the seed following double fertilization. Furthermore, in tomato (Piotto et al., 2013), macadamia (Herbert et al., 2019a, 2019b), pomegranate (Gharaghani et al., 2017; Xue et al., 2016), grape (Sabir, 2011, 2015), and litchi (Liu et al., 2011; Qiu et al.,
2006), xenia has been detected in both the seeds and fruit and thus cannot be classified into either xenia or metaxenia. The preceding research on the formation mechanisms of xenia suggests that a new xenia classification is required.

Achievements in molecular and cell biology over the past century have provided new approaches for studying the mechanisms of xenia. MicroRNA (miRNA) molecules are key regulators of posttranscriptional eukaryotic genes, which are ubiquitous in plants
(Chen et al., 2018a), highly specific, and involved in the regulation of a series of biological processes (Chen et al., 2018b; Voinnet, 2009). MiRNA molecules are capable of transferring and transporting between different cells and organisms in plants (Liu, 2008) and causing phenotypic changes in developmental tissues (Kim et al., 2001; Piotto et al., 2013). Interestingly, Engel et al. (2003) discovered that the miRNA molecules in the sperm of maize plants could move between various organs under normal or nutrient-limiting conditions (Thieme et al., 2015) and could be released and transmitted into the cellular microenvironment, resulting in more efficient signal transmission than that of hormones (Kim et al., 2001). Moreover, miRNA molecules can regulate pollen fertility and fertilization capacity in a dosagedependent manner (Akagi et al., 2014), as well as affect the fruit development, fruit size, fruit coloring, and fruit maturation period of horticultural plants (Chen et al., 2018a). Thus, it was speculated that miRNA from pollen might be transferred and expressed to the non-double-fertilized maternal tissue through intercellular transmission, thus demonstrating xenia (Kim et al., 2001).

However, the manner in which the miRNA molecules enter the fruit is unclear. Pollen is the primary cause of xenia, as its function is to produce sperm and transport it into the embryo sac for double fertilization. Differences in the seed number and contents of endogenous hormones and polyamines of the style and pulp, or in the transfer and expression of genetic information from different genotypes of pollen, can be the result of differences in vitalities of the pollen, endogenous hormones and polyamines of the pollen of different varieties, and pollination compatibilities between different varieties, which may lead to xenia. A core aspect of studying the formation mechanisms of xenia involves clarifying how the paternal 

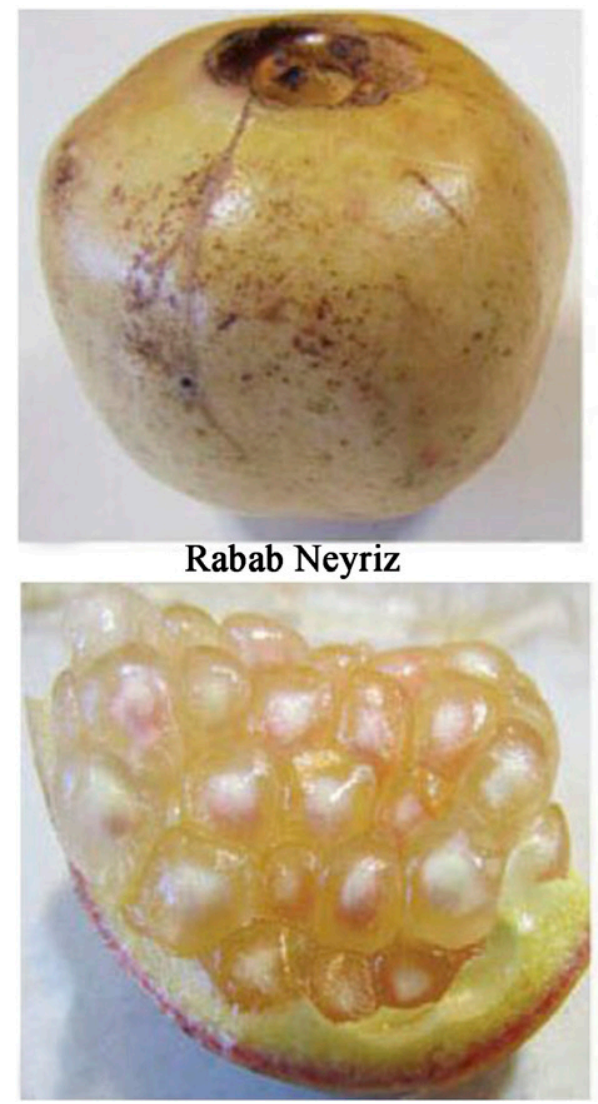

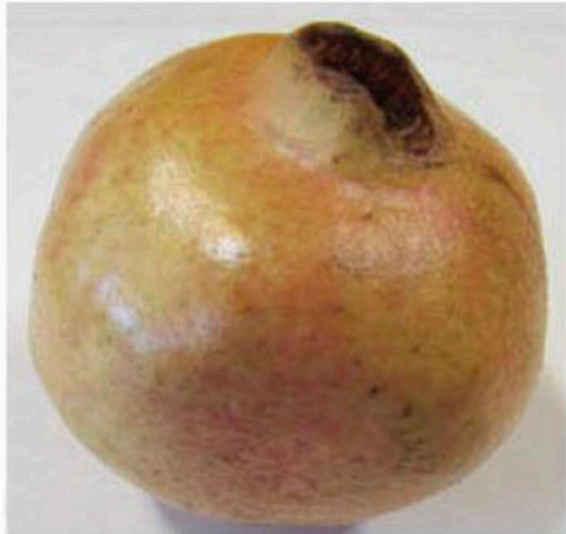

Poost Sefid Dezful

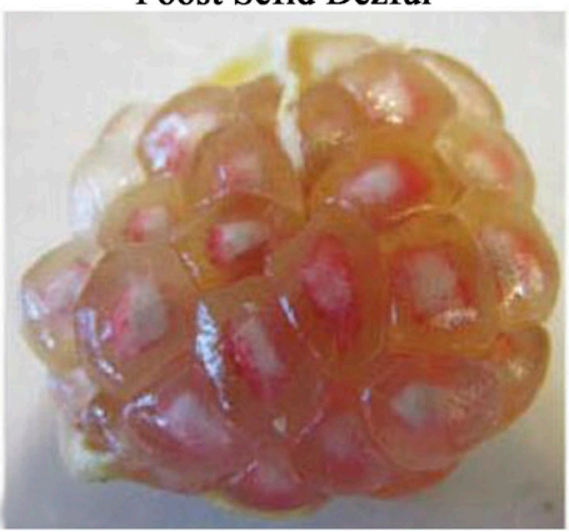

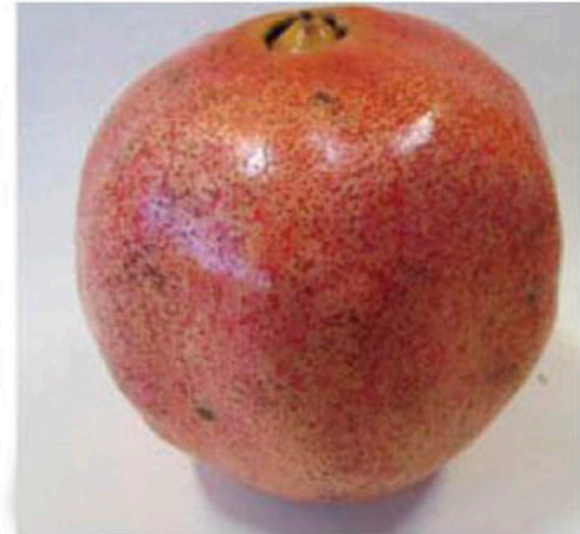

Malas Pishva Varamin

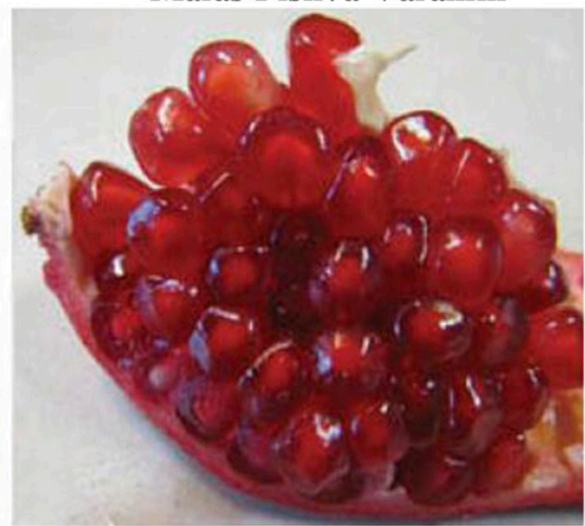

Fig. 6. Gharaghani et al. (2017) reported the effects of pollen sources from 'Rabab Neyriz', 'Poost Sefid Dezful', and 'Malas Pishva Varamin' on the peel color and aril color of 'Malas Yazdi' pomegranate. Fruit peel and aril color were affected by pollen source, and 'Malas Pishva Varamin' as the pollinizer produced fruits with greater redness than those of the other pollen sources.

information carried by the pollen can cause transcriptional expression and regulate the appearance of xenia during fruit growth and development. Although previous studies have explored the molecular mechanisms of xenia formation, they have been restricted by the existing classification, as studies focused on the xenia of the edible seed part cannot reflect whether the tissue formed by xenia obtained paternal information through double fertilization. As available studies on xenia mechanisms have been limited by the current research paradigm, three xenia types, including double-fertilization xenia, non-doublefertilization xenia, and combined xenia, were proposed in the present study. This new classification method, which addresses whether the appearance of xenia originated from the tissue formed by double fertilization, not only solves the inadequacies of the current classification but also provides a new approach for research into the formation mechanisms of xenia.

\section{Literature Cited}

Akagi, T., I.M. Henry, R. Tao, and L. Comai. 2014. A Y-chromosome-encoded small RNA acts as a sex determinant in persimmons. Science 346:646-650.

Alizadeh-Salte, S., N. Farhadi, K. Arzani, and H. Khoshghalb. 2018. Almond oil quality as related to the type of pollen source in Iranian self incompatible cultivars. Intl. J. Fruit Sci. 18:29-36.
Chen, B., J. Chen, Q. Du, D. Zhou, L. Wang, J. Xie, Y. Li, and D. Zhang. 2018a. Genetic variants in microRNA biogenesis genes as novel indicators for secondary growth in Populus. New Phytol. 219:1263-1282.

Chen, C., Z. Zeng, Z. Liu, and R. Xia. 2018b. Small RNAs, emerging regulators critical for the development of horticultural traits. Hort. Res. 5:63.

Chen, J. and H. Dong. 2017. Pollen xenia effect of high-oil maize on kernel traits of common maize. Agr. Sci. Technol. 18:1867-1869

Chen, J. and Z. Shi. 2009. Studies on pollen morphology, germination rate and fruit characteristics of Castanea mollissima in Yunnan. J. Cent. South Univ. For. Technol. 29:152-155.

Denney, J.O. 1992. Xenia includes metaxenia. HortScience 27:722-728.

Dong, H. 2007. Effect of high-oil corn pollinator on kernel quality of common corn and their physiological and biochemical basis. Shandong Agr. Univ., Taishan, Shandong, MS thesis.

Ehlenfeldt, M.K. and M. Kramer. 2012. Selffertility evaluations of northern-adapted rabbiteye blueberry hybrids. HortScience 47 : 1837-1842.

Engel, M.L., A. Chaboud, C. Dumas, and S. McCormick. 2003. Sperm cells of Zea mays have a complex complement of mRNAs. Plant J. 34:697-707.

Gharaghani, A., A.A. Ghasemi Soloklui, N. Oraguzie, and D. Zare. 2017. Pollen source influences fruit quality, aril properties, and seed characteristics in Pomegranate. Intl. J. Fruit Sci. 17: 333-348.

He, J., X.Y. Li, E.N. Jiao, Q. Luo, G.L. Dai, and B. Zhang. 2013. Study on pollen xenia effect of three wolfberry cultivars. North. Hort. (9):178-180

He, X.Y., L. Tao, S.B. Ni, L.L. Chen, H.W. Zhang, and G.H. Kong. 2016. Effects of pollen xenia on nut morphological characteristics and quality of 'O.C' cultivar in Macadamia spp. Nonwood Forest Res. 34: $76-82$.

Herbert, S.W., D.A. Walton, and H.M. Wallace. 2019a. The influence of pollen-parent and carbohydrate availability on macadamia yield and nut size. Scientia Hort. 251:241-246.

Herbert, S.W., D.A. Walton, and H.M. Wallace. 2019b. Pollen-parent affects fruit, nut and kernel development of Macadamia. Scientia Hort. 244:406-412.

Huang, R., Y. Zhang, Q. Zhang, Z. Wang, G. Xia, J. Huang, and Y. Hu. 2019. Transcriptome analysis of photosynthetic capacity of exocarp of heterogeneously pollinated Carya cathayensis. Sci. Silvae Sin. 55:128-137.

Kahriman, F., M. Şerment, M. Haşlak, and M. Kang. 2017. Pollen effect (xenia) for evaluating breeding materials in maize. Genetika 49:217234.

Kim, M., W. Canio, S. Kessler, and N. Sinha. 2001. Developmental changes due to long-distance movement of a homeobox fusion transcript in tomato. Science 293:287-289.

Kodad, O., G. Estopañán, T. Juan, and R. Socias i Company. 2009. Xenia effects on oil content and fatty acid and tocopherol concentrations in autogamous almond cultivars. J. Agr. Food Chem. 57:10809-10813.

Kumar, K. and B. Das. 1996. Studies on xenia in almond (Prunus dulcis (Miller) D. A. Webb). J. Hort. Sci. 71:545-549. 
Lee, U.Y., Y.J. Ahn, and J.P. Chun. 2017. Effect of different pollen sources on fruit characteristics and quality in 'Niitaka' pears (Pyrus pyrifolia Nakai). Korean J. Agr. Sci. 44:23-29.

Li, B.G., Y.H. Gu, S.P. Guo, S.H. Zhao, G.H. Qi, and L.P. Zhang. 2016. A study on metaxenia roles in trait expression of 2001 Fuji apple fruit. J. Agr. Univ. Hebei 27:34-47.

Li, S.M., X.Q. Su, M. Abdullah, Y.M. Sun, G.H. Li, X. Cheng, Y. Lin, Y.P. Cai, and Q. Jin. 2018. Effects of different pollens on primary metabolism and lignin biosynthesis in pear. Intl. J. Mol. Sci. 19:2273.

Liang, X., J. Chen, L. Yang, Z. Zhao, and Z. Shi. 2016a. Effect of pollination combination from northern and southern Chinese chestnut on fruiting characteristics. North. Hort. 40:4-8.

Liang, X., M. Wang, and Z. Shi. 2016b. Cloning and sequence analysis of PPDK gene in Castanea mollissima. J. Northwest For. Univ. 31:104-109.

Liu, Y. 2008. A novel mechanism for xenia? HortScience 43:706.

Liu, Y.J., Y.M. Xiong, X.K. Lu, Q.Z. Xu, Q.H. Lin, and L. Yang. 2011. Effects of pollen parents on the main characters of Dongliu No.1 litchi fruits. Chin. J. Trop. Crops 32:796-799.

Liu, Z.Q., J.H. Chen, Y.T. Zheng, and G.Q. Jiang. 2016. Effect of different pollination varieties on Qingxiang pear fruit quality. Asian Agr. Res. 8:92-94.

Lu, B., Z.X. Shao, W.M. Yang, D.L. Ning, and C.H. Du. 2004. Biological characters of chinese chestnut new lines. J. Fruit Sci. 21:176-178.

Mansur, N., R.Q. Du, X.Y. Chen, W.Q. Zhou, Y.Y. Niu, N. Ablah, and K. Liao. 2019. Pollination compatibility and pollen xenia of Xinjiang pear cultivars with 'Kuerlexiangli' pear. J. Fruit Sci. 36:447-457.

Miller, S., P. Alspach, J. Scalzo, and J. Meekings. 2011. Pollination of 'Hortblue Petite' blueberry: Evidence of metaxenia in a new ornamental home-garden cultivar. HortScience 46: 1468-1471.

Mizrahi, Y., J. Mouyal, A. Nerd, and Y. Sitrit. 2004. Metaxenia in the vine cacti Hylocereus polyrhizus and Selenicereus spp. Ann. Bot. 93:469-472.

Nie, L. and H.G. Liu. 2002. Effect of pollination on the change of endohormones in the fruit of Shatianyou pomelo variety. J. Fruit Sci. 19:2731.

Papadakis, I.E., E.E. Protopapadakis, and I.N. Therios. 2009. Yield and fruit quality of 'Nova' hybrid [Citrus clementina hort. ex Tanaka $\times(C$. reticulata Blanco $\times C$. paradisi Macfad)] and two Clementine varieties (C. clementina hort. ex Tanaka) as affected by self- and crosspollination. Scientia Hort. 121:38-41.

Piotto, F.A., K.D. Batagin-Piotto, M. de Almeida, and G.C.X. Oliveira. 2013. Interspecific xenia and metaxenia in seeds and fruits of tomato. Sci. Agr. 70:102-107.

Pozzi, F.I., G.R. Pratta, C.A. Acuña, and S.A. Felitti. 2019. Xenia in bahiagrass: Gene expression at initial seed formation. Seed Sci. Res. 29:29-37.

Prasanna, B.M., V. Chaikam, and G. Mahuku. 2012. Doubled haploid technology in maize breeding: Theory and practice. International Maize and Wheat Improvement Center, Mexico, D.F.

Qi, X., X. Zheng, H. Ren, S. Liang, H. Yan, and Y. Wu. 2017. Effect of xenia on fruit quality and sucrose metabolism enzyme activity in red bayberry. J. Fruit Sci. 34:861-867.
Qi, X.J., L.X. Han, M. Li, S.K. Xu, Y.S. Zhu, W.X. $\mathrm{Li}$, and S.R. Qiao. 2007. Studies on pollen xenia of kiwifruit. J. Fruit Sci. 24:774-777.

Qiu, Y.P., H.F. Dai, Z.-Q. Li, L.-X. Ou, X. Xiang, J.Z. Chen, and B.X. Wang. 2006. Effects of pollinator on fruit quality of Guiwei litchi cultivar. J. Fruit Sci. 23:703-706.

Sabir, A. 2011. Influence of self- and crosspollinations on berry set, seed characteristics and germination progress of grape (Vitis vinifera cv. Italia). Intl. J. Agr. Biol. 13:591-594.

Sabir, A. 2015. Xenia and metaxenia in grapes: Differences in berry and seed characteristics of maternal grape cv. 'Narince' (Vitis vinifera L.) as influenced by different pollen sources. Plant Biol. 17:567-573.

Sánchez-Pérez, R., G. Arrázola, M.L. Martín, N. Grané, and F. Dicenta. 2012. Influence of the pollinizer in the amygdalin content of almonds. Scientia Hort. 139:62-65.

Seyrek, U.A., M. Luo, M. Zhong, C. Huang, J. Tao, X. Qu, and X. Xu. 2017. Effects of stored pollens from wild Actinidia eriantha vines on some fruit quality traits. Agr. Sci. 8:465-478.

Sha, H.F., Y.D. Zhu, Q.J. Gao, and W. Zhang. 2006. Effect of xenia on fruit quality of Jingbaili pear cultivar. J. Fruit Sci. 23:287-289.

Shen, J.S., Y.W. Teng, Y.F. Chen, H.X. Wang, and X.R. Lin. 2011. Study on the xenia effect and indistinctly comprehensive evaluation of pollination combinations in Jinhua DaBai peach. J. Fruit Sci. 28:755-762.

Shi, L., X.J. Ma, J.Y. Lai, and C.M. Mo. 2008. The research advances of metaxenia effection in fruit tree. J. Guangxi Acad. Sci. 24:220-224, 230.

Stern, R.A., G. Sapir, A. Zisovich, and M. Goldway. 2018. The Japanese pear 'Hosui' improves the fertility of European pears 'Spadona' and 'Coscia'. Scientia Hort. 228:162-166.

Suaib, S. and D. Suleman. 2018. Fastest base population formation of maize through exploitation of xenia and metaxenia phenomena derived from hybrid maize varieties as parents. Asian J. Crop Sci. 10:207-213.

Taber, S.K. and J.W. Olmstead. 2016. Impact of cross- and self-pollination on fruit set, fruit size, seed number, and harvest timing among 13 southern highbush blueberry cultivars. HortTechnology 26:213-219.

Thieme, C.J., M. Rojas-Triana, E. Stecyk, C. Schudoma, W. Zhang, L. Yang, M. Miñambres, D. Walther, W.X. Schulze, J. Paz-Ares, W.-R. Scheible, and F. Kragler. 2015. Endogenous Arabidopsis messenger RNAs transported to distant tissues. Nat. Plants 1:15025.

Voinnet, O. 2009. Origin, biogenesis, and activity of plant microRNAs. Cell 136:669-687.

Wang, H., C. Wang, L. Cheng, Y. Chang, P. He, and L. Li. 2017. Effect of metaxenia on volatile compounds in bagged apple fruit of Fuji. Agr. Sci. Technol. 18:583-610.

Wang, H.B., C.Z. Wang, L.L. Cheng, Y.S. Chang, P. He, and L.G. Li. 2016. Effect of metaxenia on volatile compounds in bagged fruits of 'Fuji' apple. North. Hort (22):25-29.

Wang, M. and S. Peng. 2015. Research advances of metaxenia in Castanea mollissima. Hunan For. Sci. Technol. 42:95-98.

Wang, Q., H.Y. Gao, Y.F. Zheng, C.C. Lai, and X.G. Huang. 2018. Effects of cross-pollination on physicochemical properties, phytochemicals and antioxidant capacities of 'Fuju' (Citrus reticulate Blanco). Chin. Med. 13:107.

Wang, Z., B. Zhang, G. Xia, Y. Huang, D. Hong, and J. Huang. 2010. Analysis of the progeny of Carya cathayensis $\times$ C. illinoensis and the xenia effect. J. Fruit Sci. 27:908-913, 1073.
Xiao, Y., K.X. He, S.B. Liu, and Y.J. Tian. 2013. Effects of xenia on fruit setting and fruit qualities of Xiangji seedless kiwifruit. Hunan Agr. Sci. (19):100-102.

Xie, L., J. Hu, Q. Zhang, Q. Sun, Y. Zhang, and L. Niu. 2019. Influence of pollen sources on the expression of FA and TAG biosynthetic pathway genes in seeds of Paeonia rockii during the rapid oil accumulation. Scientia Hort. 243:477483.

Xie, L., L. Niu, Y. Zhang, M. Jin, D. Ji, and X. Zhang. 2017. Pollen sources influence the traits of seed and seed oil in Paeonia ostii 'Feng Dan'. HortScience 52:700-705.

Xu, Q., B. Wang, J. Zhao, J. Wu, Y. Cao, X. Yang, G. Xia, Z. Wang, J. Huang, and Y. Hu. 2017. Variation in photosynthetic characteristics of exocarp of Carya cathayensis fruits pollinated with different pollens. Sci. Silvae Sin. 53:38-46.

Xue, H., S.Y. Cao, J. Niu, H.X. Li, F.H. Zhang, and D.G. Zhao. 2016. Effects of xenia on fruit setting and quality in 'Tunisia' pomegranate. J. Fruit Sci. 33:196-201.

Yang, L., C. Wu, X. Wu, X. Jiang, B. Gong, Q. Hu, J. Lan, and Y. Wu. 2018. Preliminary study on effects of pollination on fruiting characters and parent selection of Castanea henryi. J. Zhejiang Agr. Sci. 59:431-435.

Yang, Q., X.Y. Li, X. Tian, L. Wei, L. Tang, J. Zhang, Y. Yue, and X.Y. Wang. 2015. Screening of the appropriate pollinizer of rabbiteye blueberry cultivar 'Powderblue'. North. Hort (6):5-7.

Yang, Q., J.L. Zhang, T.T. Zhang, X.Y. Li, S. Peng, and D.P. Li. 2017. Effects of different pollination varieties on fruit set and fruit characters of 'Britwell' rabbiteye blueberry. South China Fruits 46:93-95, 99.

Yildiz, E. and M. Kaplankıran. 2017. The effect of cross-pollination on fruit set and quality in 'Robinson' and 'Fremont' mandarins. Ege Univ. Ziraat Fak. Derg. 54:107-112.

Yu, L., L. Zuo, J. Zhang, and M. Yang. 2017. Effect of xenia on fruit quality of 4 Malus sieversii clones. Mol. Plant Breed. 15:3667-3675.

Zhang, H.P., C.H. Liu, J.L. Yao, C.H. Deng, S.L. Chen, J.J. Chen, Z.H. Wang, Q.M. Yu, Y.J. Cheng, and J. Xu. 2019a. Citrus mangshanensis pollen confers a xenia effect on linalool oxide accumulation in pummelo fruit by enhancing the expression of a cytochrome P450 78A7 gene CitLO1. J. Agr. Food Chem. 67:94689476.

Zhang, J.R., H.L. Sun, Z.C. Lu, and L. Yu. 2017. Effect of xenia on fruit quality of European plum. China Fruits (6):37-39.

Zhang, M.M., Z.H. Wang, Y.F. Mao, S.S. Chai, X.H. Zhao, Y.C. Fan, W. Ni, Z.Q. Mao, X.S. Chen, and X. Shen. 2018. Effects of different pollination combinations on the fruit quality of 'Fuji' and 'Starkrimson' apple. Sci. Agr. Sin. 51:3551-3560.

Zhang, M.M., Z.H. Wang, Y.F. Mao, Y.L. Hu, L. Yang, Y.Y. Wang, L.L. Zhang, and X. Shen. $2019 \mathrm{~b}$. Effects of quince pollen pollination on fruit qualities and phenolic substance contents of apples. Scientia Hort. 256:108628.

Zhang, X., D. Yuan, F. Zou, X. Fan, J. Tang, and Z. Zhu. 2016a. Studies on the pollen xenia of Castanea henryi. Acta Hort. Sin. 43:61-70.

Zhang, X., D. Yuan, F. Zou, X. Fan, J. Tang, and Z. Zhu. 2016b. A study on the xenia effect in Castanea henryi. Hort. Plant J. 2:301-308.

Zhou, X.T., B.W. Wang, P.Y. Che, L. Li, and C.Z. He. 2011. Advances of pollen xenia effect and its mechanism in plant. J. Shandong For. Sci. Technol. 41:113-117. 